\title{
HORTA ESCOLAR AGROECOLÓGICA: INCENTIVADORA DA APRENDIZAGEM E DE MUDANÇAS DE HÁBITOS ALIMENTARES NO ENSINO FUNDAMENTAL
}

\author{
M. J. D. DOS SANTOS ${ }^{1}$, T. A. O. DE AZEVEDO², J. L. DE O. FREIRE', D. K. L. ARNAUD'1 e F. L. A. M. REIS ${ }^{1}$ \\ ${ }^{1}$ Instituto Federal de Educação, Ciência e Tecnologia da Paraíba \\ ${ }^{2}$ Universidade Estadual da Paraíba \\ thyagoanderson2009@gmail.com
}

Artigo submetido em outubro/2013 e aceito em agosto/2014

DOI: $10.15628 /$ holos.2014.1705

\begin{abstract}
RESUMO
A horta é um laboratório vivo disponível a diferentes atividades didáticas. A sua instalação em ambientes escolares proporciona um conjunto de vantagens à comunidade escolar, como a abordagem de temas relacionados à educação ambiental e educação para a saúde através dos aspectos nutricional e alimentar. Com o objetivo de avaliar a sua ação como instrumento motivador do processo ensino-aprendizagem, de sensibilização socioambiental e de conscientização às mudanças de hábitos alimentares de alunos do Ensino Fundamental II, foi implantada, no ano letivo de 2012, uma horta escolar de base agroecológica na Escola Municipal de Ensino Tertuliano Pereira de Araújo, na zona
\end{abstract}

rural do município de Picuí, PB. As atividades laborais na horta escolar contribuíram à melhoria no processo ensino-aprendizagem em virtude de maior interdisciplinaridade, maior espírito coletivo entre os discentes e recrudescimento de qualidades superiores como a solidariedade. As atividades na horta escolar contribuíram para elevar a conscientização dos alunos sobre os problemas ambientais e permitiu a compreensão do que seja sustentabilidade. Os alunos perceberam a importância do uso das hortaliças como alimento saudável e modificaram o hábito alimentar após conduzirem as atividades na horta escolar e usufruírem das hortaliças na própria merenda.

PALAVRAS-CHAVE: Agroecologia, alimentação escolar, educação ambiental, interdisciplinaridade.

\section{SCHOOL GARDEN AGROECOLOGICAL: SUPPORTIVE LEARNING AND CHANGING EATING HABITS IN ELEMENTARY SCHOOL}

\begin{abstract}
$O$ The garden is a living laboratory available to different learning activities. Its installation in school environments provides a number of advantages to the school community, as the discussion of topics related to environmental education and education for health through food and nutrition aspects. Aiming to evaluate its action as an instrument motivator of the teachinglearning, environmental awareness and awareness to changing eating habits of elementary school students II, was implemented in the 2012 school year, a school garden-based agroecological Municipal Elementary School in Tertuliano Pereira de Araújo, in the rural
\end{abstract}

municipality of Picuí, state Paraiba. The labor activities in the school garden contributed to improving the teachinglearning process because of greater interdisciplinarity, greater collective spirit among students and resurgence of superior qualities such as solidarity. The activities in the school garden contributed to raising the awareness of students about environmental problems and allowed an understanding of what sustainability. Students realized the importance of using healthy food like vegetables and food habits changed after conducting the activities in the school garden and enjoy the vegetables in school lunches.

KEYWORDS: Agroecology, school feeding, ambientals education, interdisciplinary. 


\section{INTRODUÇÃO}

Pautada no que asseveram Brandão \& Brandão (1996), a implantação de hortas em escolas no semiárido nordestino se justifica pela possibilidade de mudanças comportamentais na alimentação e convívio social, pela necessidade de perspectivas de um futuro e um ambiente de estudo para alunos, professores e pais, gerando a inclusão social de crianças e jovens, além de gerar oportunidades de ocupação sobre sustentabilidade, aprendizagem de hábitos alimentares saudáveis, mercado informal e um campo extraclasse de atividade pedagógica.

Para Bianco \& Rosa (2002), uma horta bem organizada e planejada tem como vantagens o fornecimento de hortaliças que contêm vitaminas e minerais essenciais à saúde, possibilita uma alimentação de qualidade, saudável e variada, diminui os gastos com a alimentação escolar, permite a colaboração dos educandos, com o enriquecimento dos seus conhecimentos e aprimoramento de experiência, melhora a aparência e o valor nutritivo das refeições e permite produção em curto espaço de tempo.

A horta é um laboratório vivo disponível a diferentes atividades didáticas. A sua instalação proporciona um conjunto de vantagens à comunidade escolar, como a abordagem de temas relacionados à educação ambiental e educação para a saúde através dos aspectos nutricional e alimentar. Com isso, cumpre-se uma exigência do Ministério da Educação, que concebe como essencial o acesso ao conhecimento de forma ampla, bem como o acesso às novas tecnologias, além do estímulo às atividades que contribuam para conscientização sobre a importância da melhoria das condições ambientais, além da necessidade de serem construídas novas visões educacionais que integrem a saúde e o ambiente através de propostas interdisciplinares (IRALA \& FERNANDES, 2001; MORGADO, 2008; CRIBB, 2010).

A horta escolar pode provocar mudanças de valores e atitudes, criando na escola um espaço de formação e informação, propiciando a aprendizagem de conteúdos ao favorecer a inserção do educando no dia a dia das questões sociais, fazendo com que o mesmo seja capaz de intervir na realidade local, de modo a contribuir na reformulação de pensamentos dos atores envolvidos (FREIRE, 2008). O espaço da horta escolar é caracterizado por Capra (2005) como um local capaz de religar as crianças aos fundamentos básicos da comida e ao mesmo tempo integra e enriquece todas as atividades escolares. Com isso, a horta desperta para não depredar, mas para conservar o ambiente e trilhar os caminhos para alcançar o desenvolvimento sustentável. Prognostica-se uma maneira nova de ver os conteúdos programáticos de cada disciplina através da contextualização e interdisciplinaridade, trabalho em equipe, responsabilidade e boa relação com o meio ambiente.

No contexto escolar, identificam-se três tipos de hortas: hortas pedagógicas (tendo como principal finalidade a realização de um programa educativo preestabelecido, a horta escolar, como eixo organizador, permite estudar e integrar, sistematicamente, ciclos, processos e dinâmicas de fenômenos naturais), hortas de produção (visam complementar a alimentação escolar através da produção de hortaliças e algumas frutas) e hortas mistas (possibilitam desenvolver tanto um plano pedagógico, quanto melhorar a nutrição dos escolares, mediante a oferta de alimentos frescos e sadios) (FERNANDES, 2009). 
A escola, notadamente, a ambientada na zona rural, deve dispor dessa importante ferramenta no processo ensino-aprendizagem, instalando, no seu ambiente interno, atividades ligadas à atividade agrícola. As atividades realizadas na horta escolar de base agroecológica, por seu turno, contribuem para a compreensão dos alunos a respeito do perigo na utilização de agrotóxicos para a saúde humana e para o meio ambiente. Proporciona uma compreensão da necessidade da preservação do meio ambiente escolar, além de desenvolver a capacidade do trabalho em equipe e da cooperação. Tais atividades auxiliam no desenvolvimento da consciência de que é necessária a adoção de um estilo de vida menos impactante sobre o meio ambiente, bem como a integração dos alunos com a problemática ambiental vivenciada a partir do universo da horta escolar.

A interdisciplinaridade tem como estratégia a união de diferentes disciplinas em busca da compreensão sobre determinado assunto. Isso gera conhecimento sem o afastamento de seus conceitos e métodos, porque o ideal é que o aluno perceba que a disciplina que ele estuda tem envolvimento com temas variados, o que permite que ele faça associações dos conteúdos estudados com o meio ao qual ele está inserido. Em um processo interdisciplinar é importante que haja participação, união, espírito de grupo, engajamento, comunicação e ação (PHILIPPI JUNIOR, 2000). Morin (2002) afirma que é preciso trabalhar de forma integrada ao longo do processo ensino-aprendizagem. Como as disciplinas curriculares são compartimentadas, torna-se difícil obter um resultado significativo tanto para o aluno como para o professor. Por isso, a necessidade de reconstruir, de entrar em sintonia com o contexto dos educandos e essa possibilidade se dá através de uma unidade de aprendizagem.

Com este trabalho, objetivou-se avaliar a horta escolar de base agroecológica como instrumento motivador do processo ensino-aprendizagem, de sensibilização socioambiental e de conscientização às mudanças de hábitos alimentares de alunos do Ensino Fundamental II, no ano letivo de 2012, na Escola Municipal de Ensino Tertuliano Pereira de Araújo, na zona rural do município de Picuí, PB.

\section{MATERIAL E MÉTODOS}

\subsection{LOCALIZAÇÃO DO ESPAÇO DE APRENDIZAGEM E FORMALIZAÇÃO}

A horta escolar de base agroecológica foi implantada na Escola Municipal de Ensino Fundamental Tertuliano Pereira de Araújo, localizada no sítio Pedreiras, município de Picuí, PB que fica localizado na mesorregião da Borborema, microrregião Curimataú Ocidental com as seguintes coordenadas geográficas $06^{\circ} 33^{\prime} 18^{\prime \prime}$ Latitude Sul e $36^{\circ} 20^{\prime} 56^{\prime \prime}$ Longitude Oeste.

Formalizou-se uma parceria de ações entre o Instituto Federal de Educação, Ciência e Tecnologia da Paraíba, campus Picuí, e as Secretarias Municipais de Agricultura e de Educação do município de Picuí, PB. O trabalho teve início no dia 28 de abril de 2012 e se estendeu até o dia 20 de dezembro de 2012.

\section{PÚBLICO-ALVO}

O público-alvo contemplado com as ações da pesquisa foi composto de 300 alunos das séries do Ensino Fundamental II ( $5^{\circ}$ ao $9^{\circ}$ anos sendo 2 turmas do 50 ano, 2 turmas do 6응 ano, 3 turmas do 7음 ano, 2 turmas do 8 을 ano e 2 turmas do 9o ano) da Escola Municipal de Ensino 
Fundamental Tertuliano Pereira de Araújo, ano letivo de 2012, distribuídas em dez (10) turmas do período matutino.

A comunidade pericentral da Escola foi instigada a participar das ações em face do envolvimento já existente entre a Instituição de Ensino e a comunidade rural do sítio Pedreiras e adjacências, representada, em sua maioria, pelos pais dos discentes, com intuito de encontrar alternativa de renda ligada ao setor primário.

\subsection{ESPAÇO LABORAL: HORTA ESCOLAR DE BASE AGROECOLÓGICA}

A horta escolar foi instalada no interior do espaço físico de lazer disponível na Escola. Nesta estrutura física, foram demarcados e confeccionados 15 canteiros com dimensões úteis de 1,2 m de largura e 5,0 m de comprimento, utilizados para produção de mudas e locais definitivos para hortaliças folhosas, raízes, tuberosas e frutos, numa área útil de $200 \mathrm{~m}^{2}$.

Para o preparo e condução da horta, foram utilizadas a enxada, enxadeco, ciscador, pá de transplante, carro-de-mão, mangueira, regadores, reservatório para água, esterco bovino, sementes, mudas de hortaliças, plantas medicinais, maracujazeiro amarelo, bandejas de isopor e restos de culturas dos sítios próximos para cobertura do solo (figura 1).

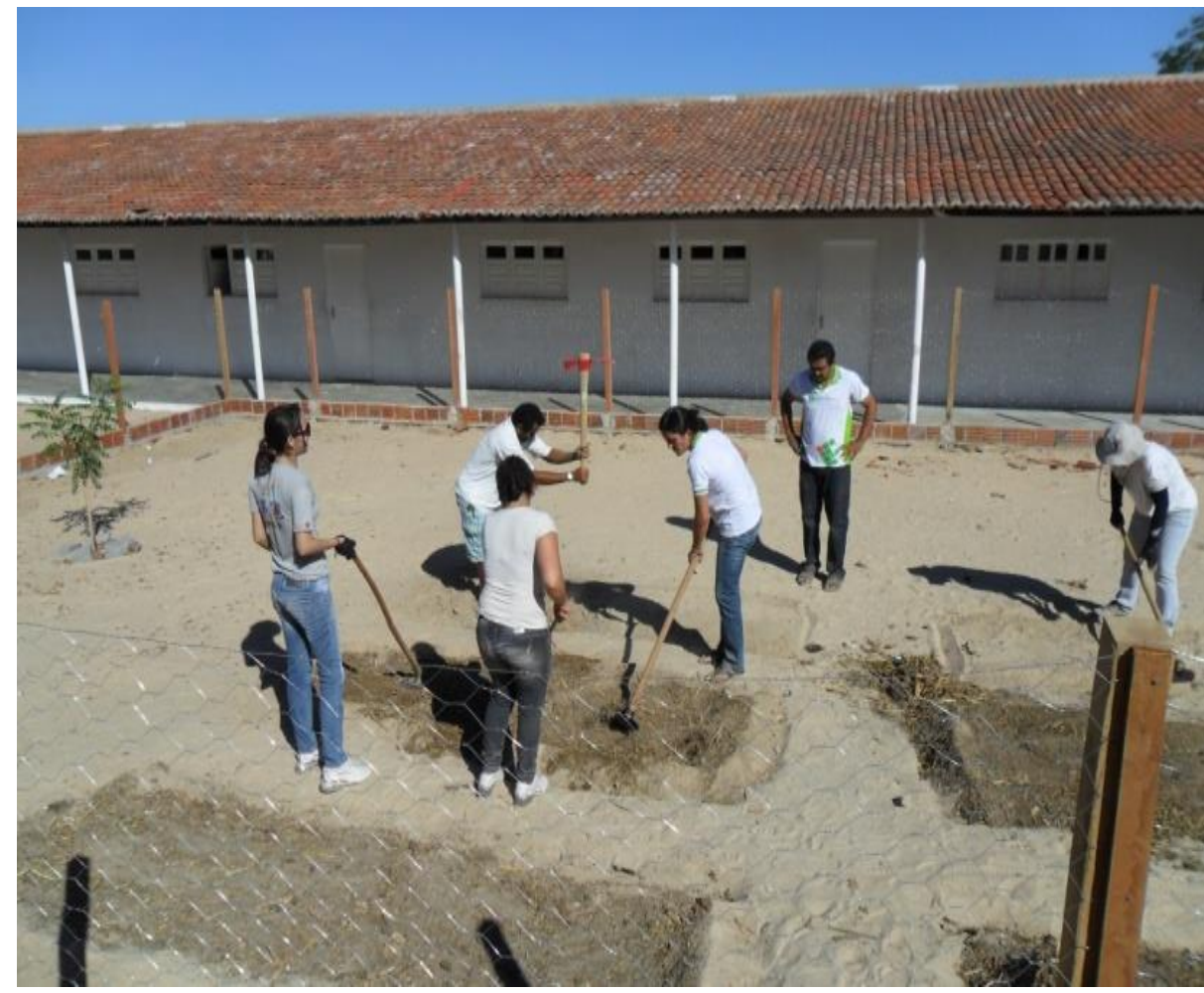

Figura 1. Demarcação e construção dos canteiros da horta escolar pelos discentes do IFPB, campus Picuí.

\subsection{AÇÕES DE CUNHO PEDAGÓGICO}

O Projeto foi apresentado à comunidade escolar da Escola Municipal de Ensino Fundamental Tertuliano Pereira de Araújo para discussão e elaboração de ações de planejamento didático interdisciplinar, com ênfase no envolvimento de atores internos e externos à Instituição, contemplando metas de maior efetividade do processo ensino-aprendizagem, despertar alunos e pais para a importância socioambiental, econômica e alimentar do cultivo de hortaliças. 
No planejamento retrocitado, inseriram-se os dias e horários das aulas expositivas de campo e atividades laborais dinâmicas na horta. Nas aulas expositivas, in loco, apresentaram-se as temáticas teóricas sobre importância alimentar das hortaliças, principais hortaliças, métodos de propagação, preparo de canteiros, adubos orgânicos, manejo de hortas, noções de pragas e doenças, colheita, rendimento, comercialização, conservação de hortaliças e culinária.

No âmbito das relações de interdisciplinaridade, foram envolvidas a Matemática, Ciências, Geografia e Artes.

A avaliação do processo ensino-aprendizagem contemplou, além das ações práticas de envolvimento no manejo e condução da horta, a elaboração de cartazes, debates e palestras ligadas à temática da produção e consumo saudável de hortaliças, ministradas pelos discentes do Curso Superior de Tecnologia em Agroecologia do IFPB, campus Picuí.

Na última etapa de cunho pedagógica, procedeu-se ao estímulo dos discentes à difusão nas suas casas dos conhecimentos técnicos sobre produção de hortaliças com base agroecológica e, por intermédio da tutora do Projeto, difusão da idéia e dos resultados preliminares no programa de rádio "Cultivando Agroecologia", através da Rádio Cenecista de Picuí.

\subsection{AÇÕES DE CUNHO LABORAL}

A horta foi implantada pelos discentes da disciplina Olericultura do Curso Superior de Tecnologia em Agroecologia do Instituto Federal de Educação, Ciência e Tecnologia da Paraíba, campus Picuí.

Nas ações práticas no laboratório vivo, os professores e discentes foram capacitados pelos monitores do IFPB, campus Picuí, em atividades de demarcação e confecção dos canteiros seguindo a modelagem dos canteiros-padrões - compostagem, adubação orgânica, preparo de mudas, época de plantio, transplantio, capinas, irrigação, reconhecimento de insetos úteis, de pragas e doenças, colheita e pós-colheita. Para os interessados na atividade da comunidade, os atores internos foram os instrumentos de multiplicação da proposta de implantação de pequenas hortas de cunho agroecológico.

Após a explanação teórica dos métodos de propagação de hortaliças pelo professor de Ciências, procedeu-se ao preparo das mudas de alface como atividade prática dos discentes do 7으 ano do Ensino Fundamental II. As sementes foram plantadas em bandejas de isopor de 128 células, utilizando-se como substrato uma mistura de esterco bovino e solo (Figura 2A). Simultaneamente, ocorreu à divisão de tarefas com outra turma, que ficou responsabilizada pelo transplantio de mudas de alface, plantio de coentro, cenoura e quiabo em locais definitivos (Figura 2B). 
A

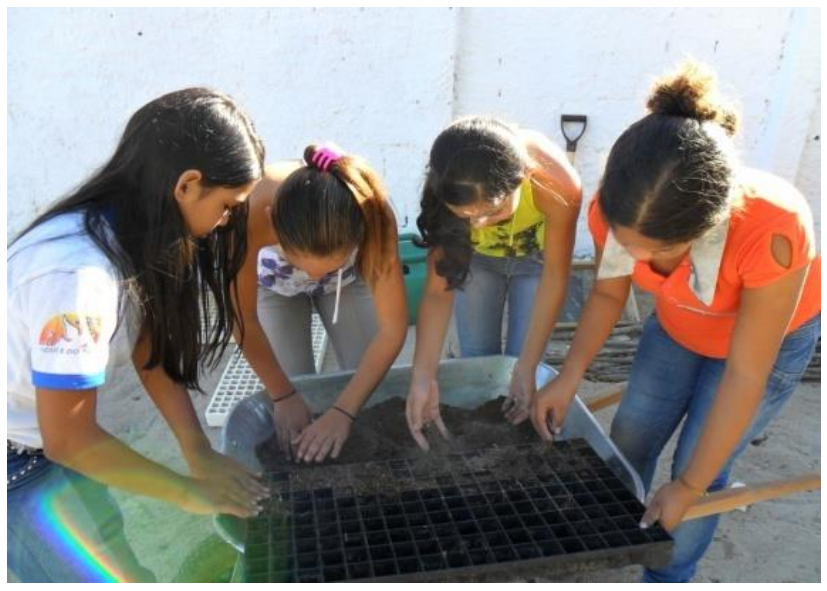

B

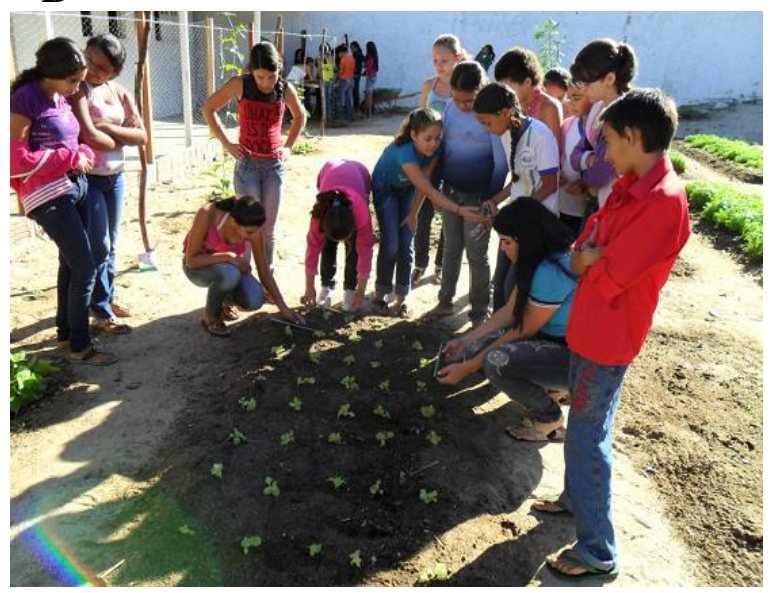

Figura 2. (A) Preparo de mudas e (B) transplantio de alface na horta escolar de base agroecológica da EMEFTA.

Para servir de quebra-vento, foram plantadas mudas de maracujazeiro amarelo (Passiflora edulis Sims) ao redor da horta. Foram preparadas mudas de alface (Lactuca sativa), beterraba (Beta vulgaris), pimentão (Capsicum annuum) e cebolinha (Allium fistulosum), também foram cultivadas na horta escolar de base agroecológica a cenoura (Daucus carota), o coentro (Coriandrum sativum), o jerimum (Curcubita moschata), e o rabanete (Raphanus sativus), além de algumas plantas medicinais disponibilizadas pelos alunos.

A adubação foi à base de esterco bovino e as irrigações realizadas com água proveniente da chuva armazenada em cisternas através de mangueiras e regadores manuais, diariamente, pela manhã pelos alunos e, à tarde, por um funcionário da Escola.

As hortaliças colhidas foram disponibilizadas à merenda escolar da Escola Municipal de Ensino Fundamental Tertuliano Pereira de Araújo.

\subsection{AVALIAÇÃO}

A avaliação final dos resultados do projeto se pautou em formulários aplicados a discentes, professores e pais dos alunos, de forma estruturada, com questões fechadas. $O$ espaço amostral correspondeu a 150 pessoas, representando uma porcentagem de $30 \%$ dos envolvidos no processo.

\section{RESULTADOS E DISCUSSÃO}

\subsection{IMPLANTAÇÃO DA HORTA}

A partir da construção, propriamente dita, da horta escolar pelos discentes do Curso Superior de Tecnologia em Agroecologia do Instituto Federal de Educação, Ciência e Tecnologia da Paraíba, campus Picuí (Figura 1), foram iniciadas as ações estratégicas, e de cunho pedagógico, que envolviam os professores e os discentes no Projeto. 


\subsection{ATIVIDADES LABORAIS E INTERDISCIPLINARIDADE: CULTIVO DAS HORTALIÇAS E MANEJO DAS HORTAS PELOS DISCENTES}

De acordo com Fiorotti et al. (2011), atividades dessa natureza com discentes nas séries iniciais possibilitam o contato direto dos alunos com a terra, haja vista que eles preparam o solo, conhecem e associam os ciclos das hortaliças desde a semeadura até á colheita, além do que despertaram o senso de responsabilidade, a divisão comunitária das tarefas, respeito ao próximo e à natureza.

Percebeu-se o engajamento dos docentes e o envolvimento, na luta pedagógica, da interdisciplinaridade. O manejo diário da horta obedeceu a um cronograma planejado por turma, cabendo ao professor da disciplina do dia e horário a incumbência de comandar as atividades e inserir o conteúdo planejado em consonância com o que pudesse ser observado na horta. A divisão das tarefas se procedia de forma que cada grupo de alunos se responsabilizasse, e cumprisse etapas como irrigação dos canteiros, preparo de mudas, controle de ervas espontâneas, observação do crescimento e desenvolvimento das plantas, adubações, colheitas e limpeza do espaço (Figura 3A e 3B).

A

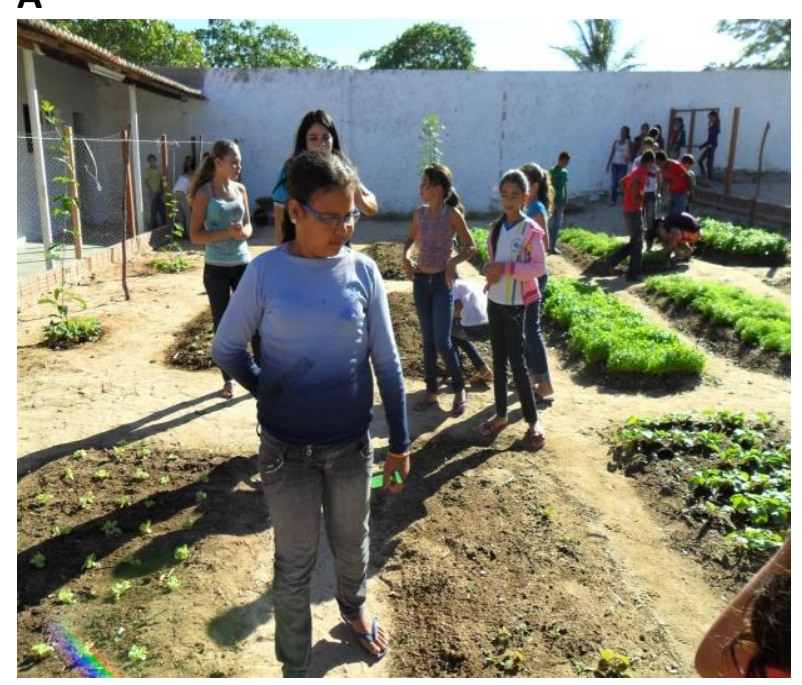

B

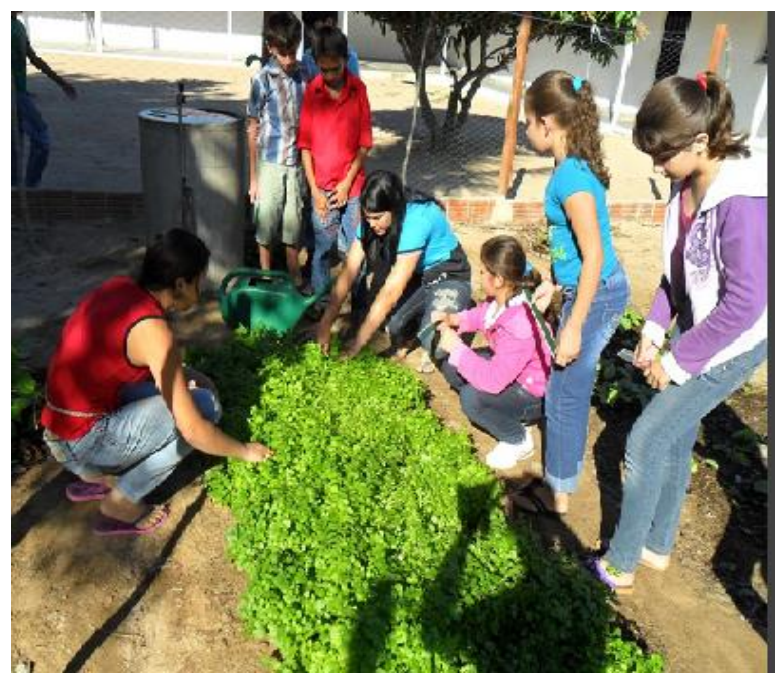

Figura 3. Tratos culturais sob a responsabilidade dos discentes do $6^{\circ}(\mathrm{A})$ e $7^{\circ}$ anos (B) do Ensino Fundamental II da EMEFTPA no município de Picuí, PB.

Num processo interdisciplinar, de acordo com Philippi Junior (2000), é importante que haja a união, a participação, o espírito de grupo, o engajamento, a comunicação e a ação. A interdisciplinaridade tem como estratégia a união de diferentes disciplinas em busca da compreensão e da resolução de um problema. Nesse âmbito, as diversas disciplinas não precisam se afastar de seus conceitos e métodos para contribuir com um projeto ou com a solução de algum problema.

No âmbito das relações da interdisciplinaridade, foram envolvidas as disciplinas Matemática (nas competências de cálculos de área envolvendo os canteiros, noções de espaço, quantificação de gasto de sementes, entre outras), Ciências (reino vegetal, valor nutricional das hortaliças, preservação ambiental, solo, micro e macrofauna, adubos orgânicos, higiene e manipulação e consumo das hortaliças), Geografia (relevo pela observação de declividade do terreno, composição do solo, fertilidade e práticas 
conservacionistas) e Artes (oficinas de receitas culinárias com alimentos procedentes da horta). Como as atividades práticas na horta escolar foram executadas no período matutino, das 7:00' e 7:50', conforme organograma citado, nas aulas precedentes eram repassados aos alunos uma síntese teórica do que seria posto em prática na aula posterior.

O professor de Matemática trabalhou com os discentes do $8^{\circ}$ ano (Figura 4), as competências de áreas e superfícies associando, in loco, a teoria com a prática da área dos canteiros da horta; noções de espaçamento entre as covas das variadas hortaliças, qual era a melhor época para o plantio, o tempo de colheita, a quantidade de adubo adequado para que haja uma terra fértil, diferenças entre cultivo definitivo e culturas de transplante.

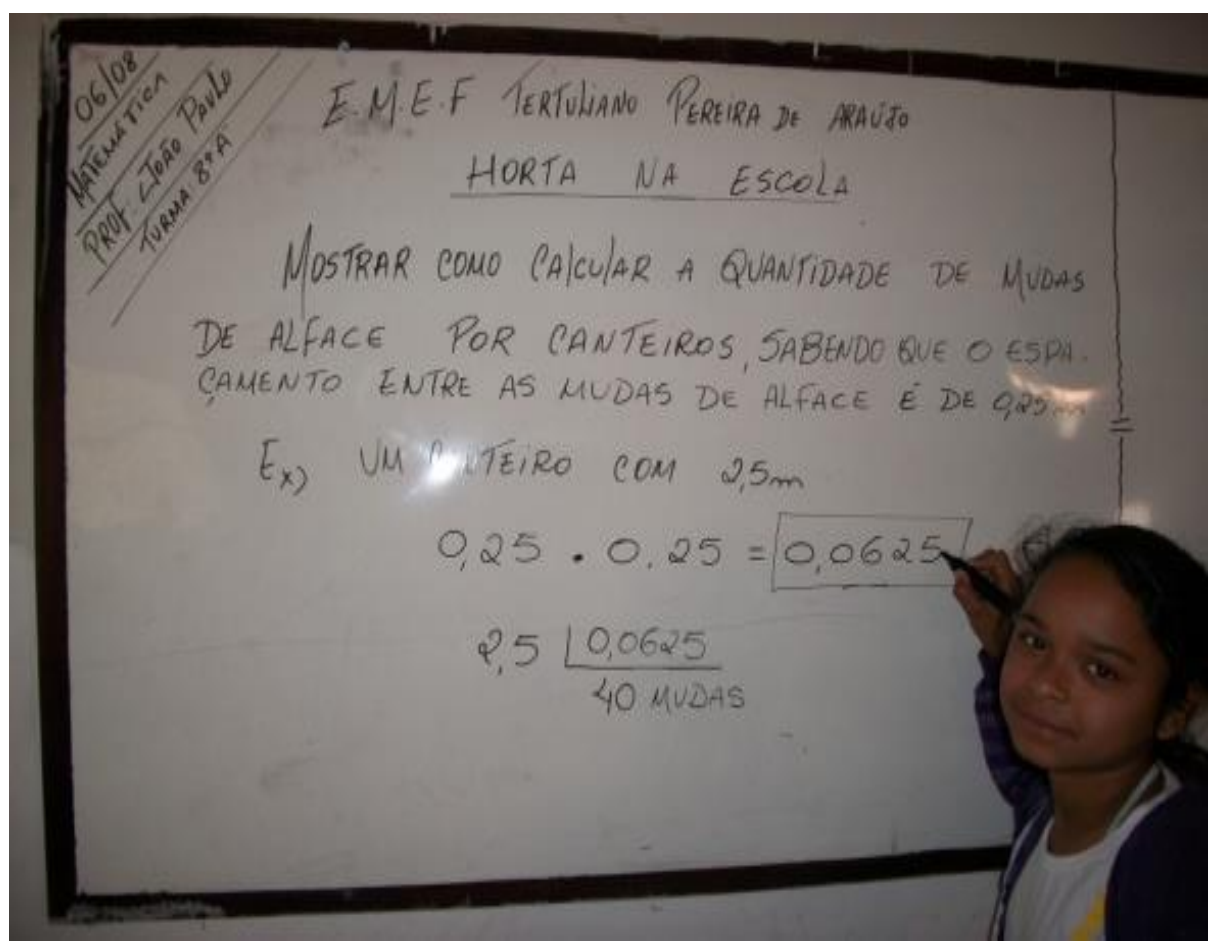

Figura 4. Estratégia de aprendizagem na disciplina Matemática no $8^{\circ}$ ano da EMEFTPA no município de Picuí, PB.

O crescimento das hortaliças estimulou o recrudescimento de formigas (Figura 5). Com isso, a professora de Ciências aproveitou a oportunidade para discutir sobre macrofauna, ordens de insetos, controle alternativo de insetos (com plantas existentes na comunidade, como hortelã e pimenta) e noções de convivência e harmonia social em decorrência da divisão social de tarefas pelas formigas. 


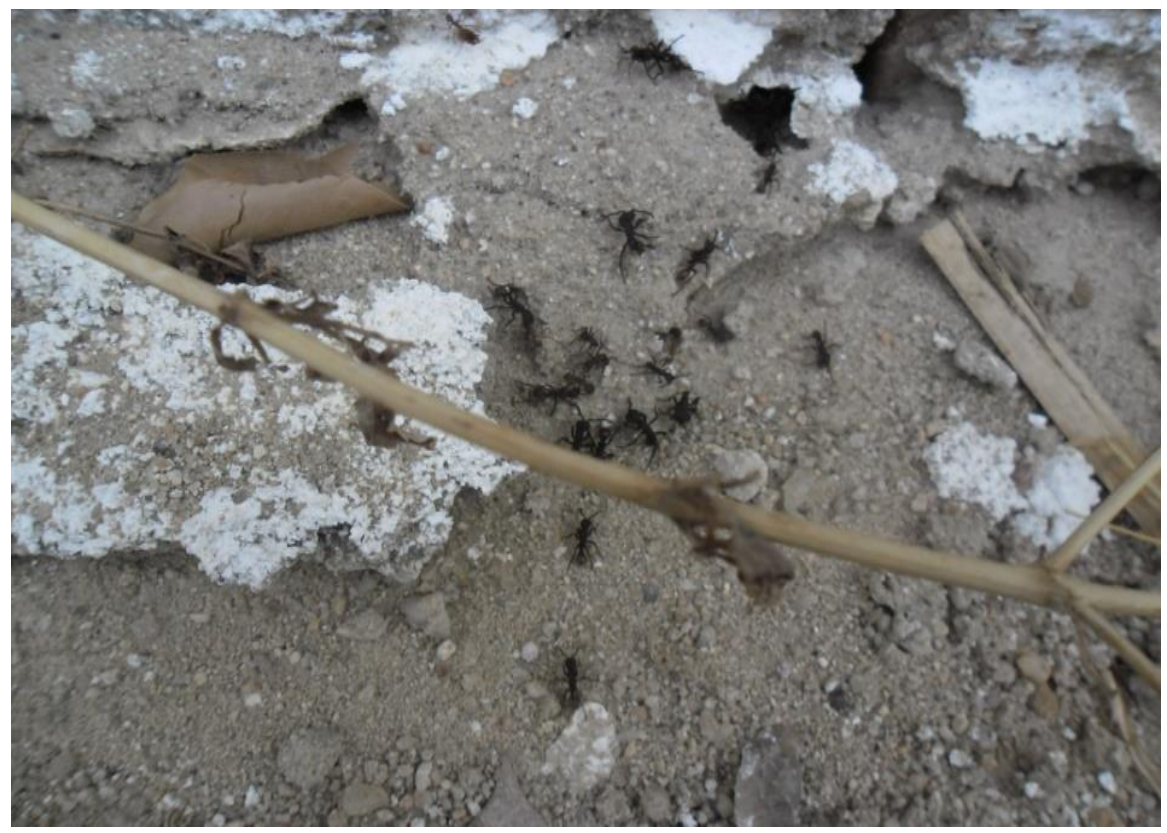

Figura 5. A ocorrência de formigas na horta serviu de laboratório vivo para aulas de Ciências.

Os benefícios da cobertura do solo e da consorciação de culturas na agricultura do semiárido nordestino foram abordados nas aulas do $6^{\circ}$ ao $9^{\circ}$ anos na disciplina Geografia. Para isso, foram aproveitados os exemplos práticos da horta escolar, onde o jerimum foi cultivado com cobertura morta.

Percebeu-se que as atividades da horta despertaram muito o espírito crítico, criativo e a curiosidade nos alunos, pois estão resgatando o cultivo da terra, estão sempre ansiosos para participarem das atividades, já que a horta se tornou novidade no ambiente em que eles estão inseridos.

\subsection{HORTA ESCOLAR COMO VITRINE MIDIÁTICA E MARKETING DA ESCOLA DE ENSINO MUNICIPAL TERTULIANO PEREIRA DE ARAÚJO}

A horta escolar da EMETPA, como instrumento motivador da aprendizagem e de modificação de hábitos alimentares na comunidade escolar, foi apresentada, através de vídeos e entrevistas com os atores ativos da comunidade escolar - mais notadamente com a participação dos alunos no Fórum do Selo Unicef, em outubro de 2012, com repercussão positiva nos debates. Membros representantes do processo avaliativo do Selo Unicef se sensibilizaram e, in loco, deslocaram-se à Escola para conhecer o Projeto.

A coordenação do Projeto concedeu entrevista no Programa Cultivando a Agroecologia, mantido pelo Núcleo de Estudos em Agroecologia, difundido semanalmente na Rádio Cenecista de Picuí, e no Programa Informativo da Prefeitura Municipal de Picuí, na mesma emissora. Nestes, foram relatadas todas as etapas do Projeto e a consecução dos resultados e reflexos iniciais nas propostas inicialmente planejadas. Ressalte-se que, ambas as entrevistas, repercutiram em toda a região do Seridó e Curimataú. 
A partir da difusão do projeto nos programas retrocitado, a coordenação foi entrevistada por blogueiros que, em efeito cascata, resultou em maior visibilidade do projeto e da Instituição de Ensino que o contempla.

Os resultados iniciais do projeto foram publicados, através do artigo "Horta escolar de base agroecológica: reflexos no processo ensino-aprendizagem e nos hábitos alimentares de alunos da zona rural de Picuí, PB" no VIII Congresso Norte e Nordeste de Pesquisa e Inovação (CONNEPI), ocorrido de 19 a 21 de outubro de 2012, em Palmas, TO.

\subsection{O ENXERGAR DOS PROFESSORES DA UTILIZAÇÃO DA HORTA NO PLANEJAMENTO ESCOLAR}

Quando indagados se a interdisciplinaridade tinha contribuído para melhoria do processo ensino-aprendizagem entre os alunos, todos os professores entrevistados (6 professores) constataram que sim. Para eles, interligar as disciplinas para mostrar aos alunos, na prática, que a realidade local pertencia aos conteúdos programáticos das disciplinas, fazendo parte do dia-a-dia de cada um, e, quando se fala de algo que se tem conhecimento é mais fácil de ser compreendido por eles.

Para Freire (2001), deve-se discutir com os educandos a realidade concreta, cujo conteúdo se ensina e indaga o porquê de não se estabelecer uma "intimidade" entre os saberes curriculares fundamental aos educandos e a experiência social que eles têm como indivíduos.

Os professores afirmaram, unanimemente, que perceberam um maior interesse às aulas quando elas se realizavam na horta. "Os alunos ficavam sempre perguntando quando era a vez deles irem à horta, até porque é uma forma nova de dar aulas, é uma fuga daquelas aulas cansativas onde o professor fica expondo o conteúdo e o aluno não tem sequer ideia do que ele está falando. Nas hortas o professor vai falando e o aluno vai observando ali mesmo o que está acontecendo", afirmou um professor.

Foi perguntado aos professores se eles achavam que o Projeto tinha proporcionado uma maior conscientização nos alunos no tocante ao meio ambiente. Para $100 \%$ dos entrevistados, percebeu-se uma mudança comportamental com relação à educação ambiental. As atitudes, até mesmo na sala de aula, haviam mudado, pois era perceptível que não havia mais papeis no chão da sala e sempre eles discutiam a respeito da necessidade da preservação do meio ambiente. "Sem contar que as atividades das hortas despertou nos alunos o trabalho em equipe, com responsabilidade e percebendo que um dependia do outro para que o trabalho ficasse bem feito", afirmou um professor.

Essa atitude reflete o que apregoa Philippi Junior (2000), para quem, num processo interdisciplinar é importante princípios como união, participação, espírito de grupo, engajamento, comunicação e ação.

Por fim, questionados como os professores enxergavam a ideia de implantar hortas escolares na zona rural, onde o público-alvo são filhos de agricultores, $100 \%$ aprovaram e achavam salutar a proliferação dos ideais desse Projeto em outras comunidades rurais. Para estes, essa iniciativa, além de ensinar os alunos a produzirem, estava demonstrando aos 
alunos o valor da profissão dos pais deles, pois muitos não consideram a agricultura como profissão.

$\mathrm{Na}$ compilação das informações contidas nos formulários, os professores relataram que o ensino-aprendizagem dos alunos melhorou significativamente, pelo crescente entusiasmo e que, em todos os conteúdos, eles procuraram associar alguma coisa com as hortas. Com esse trabalho, relatos dos pais em reuniões apontaram que os filhos têm mais orgulho de estudar na Escola. Com isto, na visão de Gallo (2001), esse trabalho possibilitou uma educação para a cidadania ao envolver metodologias interdisciplinares e incluir as questões sociais e que estas foram submetidas à aprendizagem e à reflexão dos alunos, a partir de um tratamento didático que percebeu a sua complexidade e dinâmica, atribuindoIhes a mesma importância das áreas convencionais.

Desta forma, o currículo ganha em flexibilidade e abertura, já que os temas podem ser contextualizados e priorizados. Em conformidade com o que prescreve Morgado (2008), o desenvolvimento de atividades pedagógicas resultantes da fusão teoria e prática, de forma contextualizada, na condução da horta, vem auxiliando no processo ensino-aprendizagem e estreitando relações através da promoção do trabalho coletivo e cooperado entre os agentes sociais envolvidos.

Em comunhão com o que estabelecem Fetter, Müller \& Silva (2006), observou-se o envolvimento da comunidade escolar no planejamento, execução e manutenção das hortas, levando, à mesma, princípios como horticultura orgânica, compostagem, formas de consumo dos alimentos, propriedades físicas, químicas e biológicas do solo, além da relação campocidade.

\subsection{OS BENEFÍCIOS DA HORTA ESCOLAR NA VISÃO DOS ALUNOS DA EMETPA}

Após a tabulação dos dados questionados aos alunos, organiza-se a visão que os alunos das séries do Ensino Fundamental II da EMETPA tiveram no envolvimento com as atividades, teóricas-práticas, com a horta escolar e com os resultados dela provenientes, como se segue:

$92 \%$ dos alunos avaliaram como ótima a ideia do projeto e $8 \%$ como boa. A realidade do cotidiano escolar foi modificada, pois eles passaram a ter contato com um ambiente escolar novo, inovador, com possibilidades de melhorias na sua aprendizagem e na merenda escolar;

Sobre a influência exercida pelo Projeto na mudança de hábito alimentar, 95\% dos entrevistados afirmaram como positiva e $5 \%$ não se sensibilizaram com isso. Atribui-se ao Projeto um ponto positivo e de influenciar o consumo de hortaliças. Isso era o que esperava, haja vista que o contato diário com a horta, as aulas expositivas e os debates, além da vivência e do usufruto do trabalho que, além da merenda escolar ser beneficiada com as hortaliças produzidas e colhidas por eles mesmos, o excedente de produção era distribuído para os alunos para consumirem em casa com seus familiares;

Todos os alunos entrevistados afirmaram que aprenderam plantar hortaliças, dominando os princípios básicos de plantio e cuidados com as mesmas. O empenho das turmas, que abraçaram a causa com senso de responsabilidade já demonstrava uma tendência a esses resultados. Os alunos tinham a percepção de que as plantas dependiam do zelo deles para crescerem e se desenvolverem e que todo o resultado do Projeto estava sob suas 
responsabilidades. Por isso, o domínio da tecnologia mínima de produção seria inevitável. Um aluno relatou: "Agora entendi por que minha avó ficava tão feliz ao cuidar de uma hortinha de coentro, pois ela se sentia útil e capaz de produzir alguma coisa". A preocupação de todos os atores envolvidos não foi a de propiciar uma transferência de conhecimentos sobre valores nutritivos ou técnicas que levassem os alunos a mera repetição, mas, sim, levar aos alunos informações importantes, para que o próprio educando sentisse desejo de mudar sua alimentação, para melhorá-la, sempre propiciando a conscientização e estimulando a motivação para a adoção destas práticas saudáveis, variadas e prazerosas;

Mesmo com uma rejeição inicial à ideia de consumir hortaliças na merenda escolar, $100 \%$ dos alunos se convenceram que as hortaliças são capazes de atribuir qualidade à referida merenda escolar. Com isso, presume-se que o Projeto colaborou com a formação inicial dos alunos no referente a educação alimentar, pois, agora, com um pouco mais de informação, eles poderão avaliar o que devem e precisam usar na alimentação para dominarem hábitos mais saudáveis. A ideia de plantar hortaliças na Escola, além de promover aos alunos o contato com o meio ambiente, a diversificação na merenda escolar, os ensinamentos sobre o valor nutricional das hortaliças, promovendo a multidisciplinaridade, a difusão da ideia para a comunidade que envolve no entorno da Escola a respeito de uma alimentação saudável é que, também, o excedente produzido possa ser vendido gerando renda;

$86 \%$ e $14 \%$ responderam que plantaram e não plantaram, respectivamente, hortaliças em suas casas. Depreende-se que as condições de estiagem na região tenham proporcionado solução de continuidade à ideia inicial dos alunos de exercitarem o seu aprendizado com plantios domésticos.

\section{CONCLUSÕES}

A melhoria no processo ensino-aprendizagem no Ensino Fundamental II na Escola Municipal de Ensino Tertuliano Pereira de Araújo, localizada na zona rural do município de Picuí, PB, ficou evidenciada após a implantação da horta escolar, em face de maior interdisciplinaridade, maior espírito coletivo entre os discentes e recrudescimento de qualidades superiores como a solidariedade.

As atividades na horta escolar contribuíram para elevar a conscientização dos alunos sobre os problemas ambientais e permitiu a compreensão do que seja sustentabilidade.

Os alunos perceberam a importância do uso das hortaliças como alimento saudável e modificaram o hábito alimentar após conduzirem as atividades na horta escolar e usufruírem das hortaliças na merenda escolar.

\section{REFERÊNCIAS BIBLIOGRÁRFICAS}

1. BIANCO, S.; ROSA, A. C. M. da; Instituto Souza Cruz. Hortas escolares: o ambiente horta escolar como espaço de aprendizagem no contexto do ensino fundamental : livro do professor.2. ed. Florianópolis: Instituto Souza Cruz, 2002. 77 p.

2. BRANDÃO, C. I.; BRANDÃO, R. F. Alimentação alternativa. 1996. Disponível em: 
http://manualdanovaescola.com.br. Acesso em 3 julho 2012.

3. CAPRA, F. Alfabetização ecológica: a educação das crianças para um mundo sustentável. São Paulo: Editora Pensamento/Cultrix, 2005, 102 p.

4. CARDOSO, L. Horta escolar muda hábitos e melhora o aprendizado. Disponível em: http://portal.mec.gov.br/index.php.2007. Acesso em 3 de agosto 2012.

5. CRIBB, S. L. S. P. Contribuições da educação ambiental e horta escolar na promoção de melhorias ao ensino, à saúde e ao ambiente. REMPEC - Ensino, Saúde e Ambiente, v. 3, n. 1, p. 42-60, 2010.

6. FERNANDES, M. C. A. Horta escolar. Brasília: Ministério da Educação, 2009, 43 p.

7. FETTER, S. I.; MÜLLER, J.; SILVA, M. C. Horta escolar: teoria e prática para uma vida saudável: educação ambiental na Escola Estadual João Mosmann/Parobé/RS. Revista Brasileira de Agroecologia, v. 1, n.1, 2006.

8. FIOROTTI, J. L.; CARVALHO, E. S. S.; PIMENTEL, A. F.; SILVA, K. R. Horta: a importância no desenvolvimento escolar. Anais...XIV Encontro Latino-Americano de Iniciação Científica. Universidade Vale do Paraíba, 2011. 7p.

9. FREIRE, J. L. O. Horta escolar: uma estratégia de aprendizagem e construção do cidadão. Cadernos Temáticos, v. 20, p. $93-95,2008$.

10. FREIRE, P. Educação e mudança. 24a Ed. Rio de Janeiro: Editora Paz e Terra, 2001.

11. GALLO, S. Transversalidade e educação: pensando uma educação não-disciplinar.In: ALVES, N.; GARCIA, R. L. (Orgs.) O sentido da escola. Rio de Janeiro: DP\&A,2000. Disponível em: http://www.cursoideb.utopia.com.br/index. Acesso em: 19 março 2012.

12. IRALA, C. H.; FERNANDEZ, P. M. Manual para escolas: a escola promovendo hábitos alimentares saudáveis. Brasília: Ministério da Educação, 2001, 50 p.

13. MORGADO, F. S. A horta escolar na educação ambiental e alimenta: experiência do projeto horta viva nas escolas municipais de Florianópolis, 2008 Disponível em: http://www.extensio.ufsc.br/2008/ahortaescolar.pdf. Acesso em 03 jul 2012.

14. MORIN, E. Os sete saberes necessários à educação do futuro. São Paulo: Cortez, 2002, 85 p.

15. PHILIPPI JUNIOR, A. Interdisciplinaridade em Ciências Ambientais. São Paulo: Cegos, 2000, $102 \mathrm{p}$. 